\title{
Can Adolescents Acquire Cultural Capital Through Social Capital? The Impact of Ties to College-Educated Adults
}

\author{
S. Michael Gaddis \\ mgaddis@soc.ucla.edu \\ Assistant Professor \\ Department of Sociology \\ UCLA \\ Joseph Murphy \\ jcmurph@g.ucla.edu \\ Graduate Student \\ Department of Sociology \\ UCLA
}

\section{June 2021 Draft}

\begin{abstract}
Scholars debate whether cultural capital reproduces existing inequalities or provides a path to upward mobility. Most studies, however, focus only on cross-sectional associations and are unclear about how disadvantaged adolescents can increase their amounts of cultural capital. Adolescents may be able to increase cultural capital through ties to adults with high educational attainment. We investigate this topic using experimental longitudinal data on mentoring relationships. We find that mentors with a college degree or greater have positive effects on cultural capital, but primarily for adolescents with a parent with some college or greater. Thus, cultural capital may not be an engine of social mobility if adolescents from low-SES households cannot obtain or increase their cultural capital.
\end{abstract}

Keywords: cultural capital, social capital, educational inequality, socioeconomic status

Acknowledgements: Thanks to Megan Holland, Karly Ford, and Bill Carbonaro for feedback on this paper. 


\section{INTRODUCTION}

Research on educational inequality often attempts to explain socioeconomic differences in educational achievement and attainment as a function of adolescents' backgrounds, parental investments in their children, school environments, and teachers’ attitudes and behaviors (Berkowitz et al. 2017; Domina, Penner, and Penner 2017; Entwisle and Alexander 1993; Lauen and Gaddis 2013; Sirin 2005). In many ways, cultural capital represents the intersection of these processes. Scholars suggest that cultural capital reflects assets, cultural knowledge, and linguistic competencies, all deployed with confidence and seeming naturalness that help adolescents navigate the education system that rewards this distinctly White, middle-class approach (Calarco 2018; Holland 2019; Lareau 2015; Richards 2020a). Teachers, administrators, and other institutional agents value and reward students who exhibit high levels of cultural capital. Scholars argue that cultural capital matters because it aids students in negotiating interactions with gatekeepers at every educational juncture: with their grade-school teachers (Calarco 2011, 2014), in college admissions offices (Stevens 2007), and with college professors (Jack 2019). Thus, cultural capital plays a vital role in adolescents’ and young adults’ educational achievement and attainment, where they go to college, and their later socioeconomic status (Gaddis 2015; Lee and Kramer 2013; Noble and Davies 2009; Nora 2004; Rivera 2011, 2012).

Cultural capital is one of the most examined concepts related to educational inequality. Scholars have published nearly 2,000 articles and books focused on this topic during the past five years alone. ${ }^{1}$ Research on cultural capital is deeply divided along at least three distinct lines leading to disputes about how to best interpret and operationalize Pierre Bourdieu’s (1984, 1986; Bourdieu and Passeron 1977) ideas on the topic (see Davies and Rizk 2018; Lareau and

\footnotetext{
${ }^{1}$ This information is based on our own Google Scholar search for research using the term "cultural capital” in the title. 
Weininger 2003). Arguably, a critical problem plaguing quantitative cultural capital research is the cross-sectional nature of most studies on the topic (although, see Breinholt and Jæger 2020; Gaddis 2013; Jæger and Breen 2016; and Lacoe, Painter, and Williams 2020 for longitudinal examinations). Since most quantitative studies focus on point-in-time correlations between cultural capital and outcome variables, this work is unclear on how, or even if, disadvantaged adolescents can significantly increase their amounts of cultural capital (Hu and Yin 2020).

One possible way of providing adolescents, particularly disadvantaged adolescents, with an opportunity to gain cultural capital is through ties to adults with high educational attainment. Adults who have successfully navigated the education system are likely to have high levels of cultural capital themselves and may help adolescents increase their cultural capital. These adults represent a form of social capital and may act as cultural guides by bringing more diverse knowledge, experiences, and resources through their ties to adolescents and their families (Granovetter 1973; Holland 2019; Lareau 2015; Stanton-Salazar 1997). However, research on social capital in education has rarely focused on ties between adolescents and adults outside of family or school networks (although, see Gaddis 2012; Hofferth, Boisjoy, and Duncan 1998; Morgan and Sørensen 1999) or the educational attainment of such adults, resulting in limited knowledge about this important form of social capital for adolescents.

This research examines whether adolescents' access to social capital increases cultural capital and whether this relationship varies by parents' educational attainment. We investigate this topic using unique experimental longitudinal data on mentoring relationships between adolescents and adults in the Big Brothers/Big Sisters of America program. We operationalize social capital as random assignment to an adult mentor and that mentor's educational attainment. We examine the effects of social capital on six measures of cultural capital as discussed in both 
quantitative and qualitative research: (1) reading habits, (2) museum attendance, (3) play attendance, (4) cultural lessons, (5) visiting cultural locations, and (6) relationships with teachers.

We find that only mentors with a college degree or greater have positive effects on cultural capital for adolescents. When we examine models interacting social capital with parents' educational attainment, we find that most of these effects only apply for adolescents with a parent with some college or greater. Our research merges multiple theoretical strands and provides strong causal evidence on both social and cultural capital. The results suggest that social capital can induce changes in cultural capital, but the benefits are mostly limited to adolescents with highly educated parents. This research raises serious doubts about whether adolescents from educationally disadvantaged households can increase their amounts of cultural capital valued by dominant middle-class institutions. More broadly, our findings implicate cultural capital in a system of social reproduction.

\section{LITERATURE REVIEW}

\section{Different Streams of Cultural Capital Research}

Scholars have broadly interpreted the work of Pierre Bourdieu (1984, 1986; Bourdieu and Passeron 1977) to suggest that inequalities in capital (e.g., human, social, and cultural) lead to inequalities in academic outcomes. Cultural capital is the "informal knowledge about school, traditional humanist culture, linguistic competence and specific attitudes, or personal style” that are the attributes of the dominant class (Lamont and Lareau 1988: 155). Bourdieu's theory of cultural reproduction suggests that gatekeepers block students - typically those from low socioeconomic status (SES) backgrounds - who are not familiar with the dominant culture (cultural capital) and who do not have the disposition that typically comes from such familiarity (habitus). In educational environments, teachers, administrators, and other actors value cultural 
characteristics that align with the dominant middle-class culture, which advantaged students convey through speech, attitudes, behavior, knowledge, and other interactions. However, only adolescents from middle- and high-SES backgrounds are exposed to the necessary cultural capital through their home life, interactions with their parents, and the various activities encouraged or organized by their parents. Although cultural capital helps these adolescents navigate the education system, adolescents from low-SES backgrounds may not have the dominant cultural capital expected at school and are at a distinct disadvantage. Thus, schools reproduce inequalities based on SES because institutional agents reward displays of the dominant culture, and those rewards translate into higher levels of educational achievement and attainment.

The attention to the concept pioneered by Pierre Boudieu (1984, 1986; Bourdieu and Passeron 1977) has branched into three streams of research represented by the work of Paul DiMaggio (1982; DiMaggio and Mohr 1985), Annette Lareau (1987, 2000, 2011; Lareau and Weininger 2003), and Randall Collins (2009a, 2009b, 2014) (see Davies and Rizk 2018). Much quantitative research in education flows from the DiMaggio stream and tends to focus on broad questions examining whether cultural capital reproduces existing social structures or provides opportunities for mobility (Aschaffenburg and Maas 1997; De Graaf, De Graaf, and Kraaykamp 2000; Dumais 2006; Roscigno and Ainsworth-Darnell 1999). Conversely, qualitative research in education mostly flows from the Lareau stream and examines the processes of concerted cultivation and help-seeking behavior through both home and school interactions (Calarco 2011, 2014, 2018; Holland 2015; Lareau 2000, 2011; Richards 2020a).

Quantitative Research Examining Cultural Capital and Education

Scholars in the education literature conducting quantitative research tend to operationalize cultural capital as a measure of cultural resources. The most common 
operationalizations include reading habits and participation in high-arts activities, such as museum visits and play attendance (Breinholt and Jæger 2020; DeGraaf, DeGraaf, and Kraaykamp 2000; Gaddis 2013). Additional alternate operationalizations appear in the literature, including beaux-arts possessions (Aschaffenburg and Maas 1997; DiMaggio 1982; Jæger 2009), cultural classes or lessons (Dumais 2008; Dumais and Ward 2010; Wildhagen 2009), cultural discussions and knowledge (Jæger 2009; DiMaggio and Mohr 1996; Tramonte and Willms 2010), extracurricular activities (Cheadle 2008; Covay and Carbonaro 2010; Jæger 2011), and teacher perceptions of habits and skills (Farkas et al. 1990; Farkas 2017; Kozlowski 2015). Recently, some scholars have expanded quantitative measures to better capture concepts from the qualitative literature by including operationalizations of concerted cultivation and interactions with educational institutional agents (Dumais and Ward 2010; Dumais, Kessinger, and Ghosh 2012; Matsuoka 2019).

The evidence from quantitative research consistently shows that cultural capital has positive effects on grades, test scores, and educational attainment (Aschaffenburg and Maas 1997; Bodovski and Farkas 2008; DeGraaf, DeGraaf, and Kraaykamp 2000; Dumais 2002, 2008; Gaddis 2013; Jæger 2009, 2011; Kalmijn and Kraaykamp 1996). Researchers disagree, however, whether cultural capital serves to reproduce existing structures or helps provide mobility through the education system. Prior work finds support for both the reproduction thesis (Jæger 2011; Jæger and Møllegaard 2017; Roscigno and Ainsworth-Darnell 1999) and mobility thesis (Andersen and Jæger 2015; Dumais 2006; Roksa and Potter 2011; Roksa and Robinson 2017), and mixed results as well (Aschaffenburg and Maas 1997; Dumais 2008). Moreover, these findings do not fit a clear pattern based on cultural capital measures, outcome variables, or contexts. 


\section{Qualitative Research Examining Cultural Capital and Education}

Scholars in the education literature conducting qualitative research examine cultural capital as family behavior and interactions with educational institutional agents. Rather than focusing on whether children and parents engage in specific cultural activities, qualitative researchers focus more on examining how parents and sometimes children translate knowledge, practices, and habits into educational opportunities and success. Annette Lareau's work focuses more on what parents do concerning their children and schools (1987, 2000, 2002, 2011). In Home Advantage, she examines how middle-class families work the system to solidify and increase their advantages for their children in the education system (2000). In Unequal Childhoods, she suggests that parents' child-rearing techniques of either concerted cultivation or natural growth are a critical dividing line between families of different social classes (2011). Middle-class families focus on scheduling and structuring activities so their children can gain experience valued by the education system and learn how to interact with institutional agents to get additional advantages. Lareau's (2015) follow-up work shows that adults who grew up in middle-class, compared to working-class, families were more successful at navigating bureaucracies and were more stable economically and in their relationships.

A second critical strain of qualitative research following Annette Lareau's work focuses on adolescents' help-seeking behavior and how adolescents engage with and form relationships with educational institutional agents. Researchers doing this work find that parental socialization stemming from social class influences when students seek help and how they shape strategies to do so, which results in greater ease in these interactions among middle-class adolescents (Calarco 2011, 2014, 2018; Streib 2011). The resulting inequalities from this form of cultural capital continue into higher education, leading to fewer strategies for first-generation students to 
draw upon while navigating college and more difficulties integrating into college (Armstrong and Hamilton 2013; Jack 2016; Stuber 2011; Yee 2016). Without sufficient cultural capital and appropriate strategies to navigate the higher education system, these students face a form of “culture shock” which increases stress and sense of isolation and places them at higher risk of dropping and stopping out (Aries 2008; Jack 2014; Lehmann 2007; Ostrove and Long 2007; Pike and Kuh 2005; Stephens, et al. 2012; Zarifa et al. 2018).

\section{Can Adolescents Acquire or Increase Amounts of Cultural Capital?}

While researchers generally find that cultural capital is a crucial component in educational inequality, it remains unclear whether cultural capital contributes to reproduction or mobility (Aschaffenburg and Maas 1997; DiMaggio 1982). This lack of clarity is, perhaps, due to limited research addressing whether cultural capital can be acquired or increased (Hu and Yin 2020). Qualitative research captures cultural capital as a relational concept better than quantitative research (Davies and Rizk 2018). However, while qualitative researchers examine the interaction processes leading to the use of cultural capital, they do not measure amounts of cultural capital nor find that adolescents from lower- and working-class families can systematically obtain cultural capital. Conversely, although quantitative researchers are wellpositioned to examine changes in amounts of cultural capital, the vast majority of quantitative cultural capital research is based on point-in-time rather than longitudinal examinations.

However, a limited number of studies have bucked these trends and directly or indirectly examined whether and how adolescents can obtain or increase amounts of cultural capital. Two such qualitative studies stand out. The first examines how cross-class cultural mentors may provide working-class families with resources and tools for interacting with educational institutional agents (Lareau and Calarco 2012). While working-class families sometimes have 
opportunities to interact with middle- and upper-class parents in a consistent and sustained environment (e.g., during Little League games), these interactions yield limited benefits for working-class families. A second qualitative study examines the different ways that low-SES students interact with educational institutional agents in college (Jack 2016). This research suggests that low-SES students can gain cultural capital when exposed to upper-class peers exhibiting cultural capital at elite prep schools. This form of cultural capital benefits low-SES students by preparing them for interactions with professors and administrators in higher education.

Finally, three additional quantitative studies, including two field experiments, provide additional insight on whether students can acquire or increase cultural capital. Using the multiwave longitudinal Panel Study of Income Dynamics (PSID), Roksa and Potter (2011) examine differences in cultural capital among parents whose class positions changed or stayed the same over their lifetimes. They find that upwardly mobile (from low- to middle-SES) parents can adopt practices of concerted cultivation and help their children gain cultural capital. Two field experiments provide strong causal evidence suggesting that adolescents can acquire and increase cultural capital. In the first, students randomly assigned to attend an art museum were more likely than students in the control group to want to acquire more cultural capital and attend the same museum again (Kisida, Greene, and Bowen 2014). In the second, students randomly assigned to attend a theatre play were more likely than students in the control group to want to acquire more cultural capital (Greene et al. 2018).

These five studies provide insight into whether adolescents can acquire or increase amounts of cultural capital; however, they are far from definitive for a few reasons. While the two qualitative and two experimental studies examine potential causal mechanisms of cultural 
capital acquisition, the fifth study (Roksa and Potter 2011) does not specify precisely how cultural capital acquisition might occur. Each of the other four studies examines only a specific mechanism through which adolescents might acquire or increase cultural capital. Moreover, each study examines a specific context - two in northwest Arkansas (Greene et al. 2018; Kisida, Greene, and Bowen 2014). Finally, none of these studies outline clear, general, accessible pathways that parents or adolescents might easily pursue to acquire or increase cultural capital. Acquiring or Increasing Cultural Capital through Social Capital

Although not systematic, the literature on cultural capital acquisition hints at a possible way for parents and adolescents to acquire or increase cultural capital. In the proper context, connections to and interactions with other middle- and upper-SES adults might help adolescents acquire or increase cultural capital. These connections are a form of social capital, which can generally be defined as access to and use of resources available in network connections (Bourdieu 1986; Coleman 1988, 1994; Lin 2002, 2008; Portes 1998). Similar to cultural capital, scholars have used the concept of social capital in a wide array of disciplines, subfields, applications, and analyses. We merge two important strands of social capital research to suggest how social capital might lead to cultural capital acquisition. We draw from studies on social capital in education (e.g., Coleman 1988; Stanton-Salazar 1997) and networks and employment (e.g., Lin, Ensel and Vaughn 1981; Pedulla and Pager 2019). Our inequality- and networkcentered theory of social capital helps illuminate important potential mechanisms of cultural capital acquisition.

Social Capital in the Education Literature

Research on social capital in the education literature originates from Pierre Bourdieu's (1986) and James Coleman's (1988) theoretical and empirical work on the topic. The former 
focuses on access to institutional resources, while the latter focuses on norms (Dika and Singh 2002). Thus, scholars have operationalized social capital in the education literature in a variety of ways. Work in this vein has examined social capital as intergenerational closure (Carbonaro 1998; Morgan and Sørensen 1999), parents’ relationships with other adults (Horvat, Weininger, and Lareau 2003), parents’ involvement at school (McNeal 1999; Ream and Palardy 2008), adolescents’ extracurricular activities (Broh 2002), or resources through adolescents' friends (Cherng, Calarco, and Kao 2013).

Ricardo Stanton-Salazar proffers a different version of social capital. Stanton-Salazar suggests that relationships with institutional agents are social capital (1997, 2001, 2011). His view of institutional agents is expansive - these agents include teachers, counselors, and anyone else who has "the capacity and commitment to transmit directly, or negotiate the transmission of, intuitional resources and opportunities” (1997: 6). Stanton-Salazar suggests that these institutional agents can provide seven different forms of knowledge that help adolescents navigate and succeed in the education system. He tested these theories with data from in-depth interviews, focusing on Mexican-origin adolescents from working-class families. StantonSalazar, however, never explicitly tested whether the educational attainment level of network connections (i.e., social capital) mattered, nor whether this social capital affects adolescents' cultural capital (Stanton-Salazar 2001; Stanton-Salazar and Dornbusch 1995; Stanton-Salazar and Spina 2003).

Other researchers have examined social capital in a framework similar to Ricardo Stanton-Salazar using qualitative methods. Findings from this work suggest differences by race/ethnicity and SES in access to social capital, both in terms of the types of social capital adolescents can access and the value of that capital (Hardie 2015, 2018). Black, Hispanic, and 
low-SES students have limited valuable social capital and often rely on educational institutional agents, such as counselors and teachers, to mobilize resources. These students may have few options, beyond counselors and teachers, of other adults to talk to about the college application and financial aid processes. While some research suggests counselors can positively contribute to college planning for Black, Hispanic, and low-SES students (Farmer-Hinton 2008; McKillip, Rawls, and Barry 2012; O’Connor 2000; Stanton-Salazar 2011), others find that these relationships are often only marginally beneficial due to misunderstandings and lack of trust between disadvantaged students and counselors (Holland 2015, 2019).

Education scholars have examined social capital in a variety of ways; however, very few have examined the role of important adults beyond those within the family and school. Some research has considered social capital as natural or informal mentors and examined their impact on adolescents' educational attainment and achievement (DuBois and Silverthorn 2005; Erickson, McDonald, and Elder 2009; Miranda-Chan et al. 2016). These studies, however, include family members, teachers, and other important adults in their measurements of social capital. Moreover, causality among these and other lines of social capital research is difficult to establish due to non-random selection into these relationships (Eby et al. 2008; McDonald and Lambert 2014; McDonald et al. 2013; Mouw 2006).

Social Capital in the Networks and Employment Literature

The education literature on social capital has rarely focused on the importance of unrelated adults and others beyond teachers and counselors in assisting adolescents. Moreover, this work has overlooked theoretical insight from social capital work in the networks and employment literature. An adolescent's connection to an adult may be one part of social capital; 
however, that adult brings embedded resources to the relationship that are, perhaps, an even more critical aspect of social capital.

Research on labor market outcomes, however, has examined the importance of similar types of social capital and consistently finds benefits from weak ties - individuals within a network dissimilar from the focal respondent. Mark Granovetter (1973) suggests that two fundamental social relationships exist based on either strong or weak ties. Strong ties occur between close family members and friends, whereas weak ties occur through relationships with acquaintances or friends of friends. Weak ties form a network of heterogeneous members that creates valuable social connections and makes upward mobility possible. Expanding on Granovetter's work, Lin, Ensel, and Vaughn (1981:395) explain that social resources (capital) are "embedded in the positions of contacts an individual reaches through his social network." In their research, the authors found that men in the labor force obtained higher status jobs indirectly through weak ties. Weak ties lead to higher status individuals that lead to higher status jobs because weak ties represent contacts who are a different social class from the individual (also see Lin, Vaughn, and Ensel 1981).

Numerous studies of labor market inequality have investigated social capital and embedded resources (Castilla, Lan, and Rissing 2013; Mouw 2003; Trimble and Kmec 2011). A recent theoretical development with a strong corollary to our work concerns network placement. In employment, as Pedulla and Pager (2019: 988) explain, network placement captures the idea that "strategically placed social ties may provide job seekers with tacit, informal knowledge about the companies and jobs to which they are applying." In other words, the concept of network placement provides specificity in the potential value of social capital in employment contexts. This concept translates to education in that the value an adult provides in determining 
an adolescent's educational success should account for the educational attainment of that adult. For example, an adult with a high school degree may serve as a role model and help adolescents in other ways; however, they may be unable to provide crucial knowledge about navigating the education system.

Some scholars have suggested similar ideas, particularly in reference to "cultural guides" to help adolescents navigate the education system (Gonzales 2011, 2016; Holland 2019; Lareau 2015; Lareau and Calarco 2012; Stanton-Salazar 1997; Vallejo 2012). However, this research often focuses only on standard educational institutional agents - such as teachers and counselors - and does not systematically examine differences by the educational attainment of these important adults. One potential disadvantage to prior research is that teachers and counselors act as gatekeepers, subjective decision-makers, and social capital for adolescents. Perhaps, for an adolescent to receive maximum benefit from social capital, that adult must be an outsider who has successfully navigated the system rather than a part of the education system.

The social capital literature on networks and employment suggests that the best social capital for a disadvantaged adolescent may be an adult with a college education. A collegeeducated adult, who has successfully navigated the education system and is likely to understand the importance of cultural capital, may prove especially beneficial to adolescents with parents who did not attend college.

\section{CONTRIBUTION AND RESEARCH QUESTIONS}

Most quantitative cultural capital research uses cross-sectional rather than longitudinal data. Thus, quantitative work presents unclear causal evidence of whether disadvantaged adolescents can significantly increase their amounts of cultural capital. We bring together two theoretical strands on social capital and suggest that college-educated adults may provide 
adolescents with opportunities to increase their cultural capital. Unlike prior work in education on social capital, we examine other adults who are not related to the focal adolescents and are not teachers or counselors. Additionally, more than just the existence of social capital, we focus on the content of social capital and analyze whether the educational attainment of an adult matters. We build on social capital and cultural capital research by using experimental longitudinal data that capture multiple measures of cultural capital at two times points and causal effects of social capital. Our two primary research questions are:

(1) Does social capital - operationalized as random assignment to an adult mentor and that mentor's educational attainment - affect an adolescent's levels of cultural capital?

(2) Are the effects of social capital on cultural capital, if any, dependent on an adolescent's parents' educational attainment?

\section{DATA AND METHOD}

Sample

We examine our research questions using data on adolescents who participated in the Big Brothers/Big Sisters of America program (BBBSA) during the early-to-mid 1990s. BBBSA program staff worked with Public/Private Ventures on an experimental design and matched adolescents with an adult mentor in eight cities - Columbus, Ohio; Houston, Texas; Minneapolis, Minnesota; Philadelphia, Pennsylvania; Phoenix, Arizona; Rochester, New York; San Antonio, Texas; and Wichita, Kansas. Staff did not significantly alter the typical BBBSA matching policies and procedures except to include a control group for adolescents who were not matched with mentors by staff. Instead, staff placed these adolescents in the control group on a waiting list. 
Researchers took a random sample of adolescents from existing BBBSA applicants, 959 of whom completed a baseline interview (before random assignment) and a follow-up interview (eighteen months later). The staff assigned 472 adolescents to the control group and 487 to the treatment group, 378 of whom received treatment (i.e., matched to an adult mentor).

Table 1 shows the descriptive statistics for our sample. The mean age of adolescents at the beginning of data collection in our sample is 12.3 , and the range is 9.4 to 16.7 . The sample skews male (62.5\%) and has nearly as many Black adolescents (40.8\%) as White adolescents (42.3\%). It is important to note the nature of disadvantage in this sample. Although the criteria differ by chapter, the BBBSA program attempts to help the most disadvantaged children and adolescents. Nearly $83 \%$ of the sample live in households making less than $\$ 25,000$ per year, and most live in a single parent or non-parental household (see Tierney, Grossman, and Resch 1995 for more information). This sample is skewed towards low-SES families and is not nationally representative. Importantly, however, there are no statistically significant differences on any of our control or pre-treatment variables between the three categories of social capital (more below). Although the sample is not generalizable to all adolescents in the U.S., the experimental nature of these data allows us to examine the effects of social capital on cultural capital for disadvantaged adolescents in a causal framework absent traditional problems of selection bias (Mouw 2006).

$$
<\text { insert Table } 1 \text { about here> }
$$

\section{Variables}

The dataset contains many adolescent characteristics, including the following variables that we use as our controls: age, gender, race/ethnicity, parents' educational attainment, learning disability status, and GPA at baseline. Our independent variable of interest - social capital - is 
operationalized as a combination of treatment status and mentor's educational attainment. Each adolescent has an equal chance of being randomly assigned to a mentor. We trichotomized mentor status as (1) no mentor, (2) mentor with some college education (but no degree) or less, and (3) mentor with a college degree or more. ${ }^{2}$ Arguably, this operationalization aligns well with the rich theoretical work of Mark Granovetter (1973), Nan Lin (2002, 2008; Lin, Ensel, and Vaughn 1981), and others by capturing both access to social capital and gradations in the embedded resources.

We examine six operationalizations of cultural capital as our dependent variables of interest: weekly hours spent reading, the number of times an adolescent has visited a museum in the past 12 months, the number of times an adolescent has attended a play in the past 12 months, the average number of cultural lessons outside of school (i.e., music, art, dance, and language), the frequency that adolescents visited cultural locations in the past 18 months (e.g., library, museum, or a play), and whether adolescents stated that they learned to get along better with teachers in the past 18 months. Each of the first four cultural capital measures was recorded before treatment assignment and eighteen months later, while the last two were only recorded during the follow-up.

Our first five measures of cultural capital best align with traditional quantitative operationalizations of cultural capital in the literature, although debate continues as to whether other measures could be more useful (see discussion in Gaddis 2013; Sablan and Tierney 2014). However, our sixth measure is closely related to an operationalization of cultural capital in recent qualitative work: the concept of help-seeking behavior (Calarco 2011, 2014; Lareau 2015;

\footnotetext{
${ }^{2}$ Robustness checks using income categories instead of college education yield similar results. However, educational attainment is the crucial theoretical link to Bourdieu's concepts of cultural capital and habitus. 
Richards 2020). This multi-faceted approach to measuring cultural capital should provide a more robust examination of the effects of social capital on cultural capital.

We use multiple imputation to address missing data. In each imputation model, we include the control and other independent variables listed in each of the main regression tables. We impute interaction values using an approach recommended by Allison (2002) in which we first create all relevant interaction variables and then impute values for any missing variables. Analytic Strategy

We analyze longitudinal models that include lagged dependent variables to adjust for omitted variable bias. In each model, we also include the individual-level controls listed above and geographic location (city). We estimate a multilevel model with a random intercept for chapter or location due to the nested nature of the data (individuals $i$ nested within BBBSA chapters $j$ ). Presented in generalized form, the longitudinal model is:

$$
\boldsymbol{Y}_{\mathrm{ij} \text { post }}=\zeta_{\mathrm{j}}+\mu_{\mathrm{i}}+\beta_{1} \boldsymbol{S} \boldsymbol{C}_{\mathrm{i} j}+\beta_{2} \boldsymbol{X}_{\mathrm{ij}}+\beta_{3} \boldsymbol{Y}_{\mathrm{ij}} \text { pre }+\varepsilon_{\mathrm{ij}}
$$

where $\zeta$ is a level 2 (location) intercept, $\mu$ is a level 1 (individual) intercept, $\boldsymbol{S C}$ is the social capital variable, $\boldsymbol{X}$ is a vector of control variables, $\boldsymbol{Y}_{\text {pre }}$ is the lagged dependent variable, and $\varepsilon$ is the error term. We estimate separate models for each of the six dependent variables.

Additionally, we model interactions between social capital and parents' educational attainment to test whether the effects of social capital vary by and parents' educational attainment. Presented in generalized form, this model is:

$$
\boldsymbol{Y}_{\mathrm{ij} \text { post }}=\zeta_{\mathrm{j}}+\mu_{\mathrm{i}}+\beta_{1} \boldsymbol{S C} \boldsymbol{*} \boldsymbol{P A R E} \boldsymbol{D}_{\mathrm{ij}}+\beta_{2} \boldsymbol{X}_{\mathrm{ij}}+\beta_{3} \boldsymbol{Y}_{\mathrm{ij}} \text { pre }+\varepsilon_{\mathrm{ij}}
$$

where $\boldsymbol{S C A}$ *PARED is an interaction that captures six possible categories of social capital and parents' highest educational attainment - parent with a high school degree or less and no mentor, parent with some college or more and no mentor, parent with a high school degree or less and a 
mentor with less than a college degree, parent with some college or more and a mentor with less than a college degree, parent with a high school degree or less and a mentor with a college degree or greater, and parent with some college or more and a mentor with a college degree or greater.

\section{RESULTS}

Table 2 presents the effect of social capital (treatment status and mentor's educational attainment) on each cultural capital variable. In model 1, we examine the effect of social capital on reading habits post-treatment. The results indicate that having a mentor with less than a college degree has no significant effect on time spent reading. Having a mentor with a college degree or greater has a significant and positive effect $(0.497 ; \mathrm{p} \leq 0.05)$ on time spent reading. In model 2, we examine the effect of social capital on museum visits post-treatment. The results indicate that having a mentor with less than a college degree has no significant effect on museum visits. Having a mentor with a college degree or greater has a significant and positive effect $(0.143 ; p=0.07)$ on museum visits. In model 3 , we examine the effect of social capital on play attendance post-treatment. The results indicate that having a mentor of any educational attainment has no significant effect on play attendance. In model 4, we examine the effect of social capital on the number of cultural lessons at post-treatment. The results indicate that having a mentor with less than a college degree has no significant effect on the number of cultural lessons. Having a mentor with a college degree or greater has a significant and positive effect $(0.196 ; p=0.07)$ on the number of cultural lessons. In model 5 , we examine the effect of social

capital on cultural location visits at post-treatment. The results indicate that having a mentor with less than a college degree has no significant effect on cultural location visits. Having a mentor with a college degree or greater has a significant and positive effect $(0.369 ; \mathrm{p} \leq 0.05)$ on cultural 
location visits. In model 6, we examine the effect of social capital on whether adolescents report that they have learned to get along better with teachers in the past eighteen months. The results indicate that having a mentor of any educational attainment has no significant effect on getting along better with teachers.

The results from Table 2 provide some moderate evidence that adolescents who have access to a highly educated adult other than their parents or teachers can increase their cultural capital. However, this relationship may vary by an adolescent's social background. In Table 3, we examine the effect of social capital interacted with parents' educational attainment on each cultural capital variable. In model 1 , the results indicate that the only significant effect of social capital on time spent reading is for adolescents who have a mentor with a college degree or greater and a parent who has a high school degree or less $(0.632 ; \mathrm{p} \leq 0.05)$. In model 2 , the results indicate that the only significant effect of social capital on museum visits is for adolescents who have a mentor with a college degree or greater and a parent who has some college or greater $(0.281 ; \mathrm{p}=0.08)$. In model 3 , the results indicate no significant effects of social capital on play attendance for any adolescents. In model 4, the results indicate a positive effect on the number of cultural lessons for adolescents who have a mentor with a college degree or greater and a parent who has some college or greater $(0.873 ; \mathrm{p} \leq 0.001)$. In model 5 , the results indicate that the only significant effect of social capital on cultural location visits is for adolescents who have a mentor with a college degree or greater and a parent who has some college or greater $(0.651 ; p \leq 0.09)$. Finally, in model 6 , the results indicate a positive effect on getting along better with teachers for adolescents who have a mentor with less than a college degree and a parent who has some college or greater $(0.766 ; \mathrm{p}=0.06)$. 
The regression results are not necessarily intuitive due to the different baseline values of cultural capital for each group and the interaction effects. Thus, in Figures 1 through 6, we graph the baseline mean for each of the first four cultural capital outcome variables ${ }^{3}$ and the predicted values by the interaction between social capital and parental educational attainment for each of the six cultural capital outcome variables. These figures show the difference in time trends due to adolescents’ different social capital and parental educational attainment. Lighter-colored bars indicate the effects for adolescents with a parent who has a high school degree or less. In contrast, darker-colored bars indicate the effects for adolescents with a parent who has some college or more.

Figure 1 shows that adolescents with a parent who has a high school degree or less significantly increase their time spent reading only when they have a mentor with a college degree or greater. These adolescents increase reading time by approximately $24 \%$ over their baseline level. For adolescents with a parent who has some college or greater, reading levels are relatively flat over time. These adolescents experience no significantly different increase in reading time from any type of mentor.

Figure 2 shows that adolescents in each parental education group undergo a reduction in museum visits over time. However, that reduction is significantly attenuated for adolescents with a parent with some college or greater and a mentor with a college degree or greater. These adolescents experience a decrease in museum visits of approximately $4 \%$ compared to $28 \%$ for adolescents without a mentor.

Figure 3 shows that adolescents in each group experience a reduction in play attendance over time; however, none of the results are significant. Figure 4 shows that most adolescents

\footnotetext{
${ }^{3}$ The baseline survey did not include the underlying survey question for the fifth and sixth outcome variables (i.e., cultural location visits, get along better with teachers). 
continue to engage in cultural lessons at similar or slightly reduced rates over time. However, adolescents with a parent with some college or greater experience the largest differences depending on their social capital. Among these adolescents, those with no mentor experience a decrease in cultural lessons of approximately 32\%, while those with a mentor with a college degree or greater experience an increase in cultural lessons of approximately 34\%.

Figure 5 has no baseline results for comparison. Among adolescents with a parent with a high school degree or less, there are no differences across the three levels of social capital. However, among adolescents with a parent with some college or greater, those with a mentor with a college degree or greater are more likely than their peers to report visiting cultural locations “sometimes” or “pretty often.” Finally, Figure 6 also has no baseline results for comparison. Among both groups of adolescents, there are no differences across the three levels of social capital.

\section{DISCUSSION}

A vast literature in education has examined the influence of cultural capital in educational achievement and attainment. Few quantitative studies of cultural capital, however, have used longitudinal data. Thus, debate exists as to whether adolescents and their families - particularly disadvantaged adolescents - can acquire and increase their amounts of cultural capital. In this research, we merged theories of social capital to create a framework suggesting that adolescents might form relationships with unrelated adults who are not teachers or school counselors to increase their cultural capital. Furthermore, we proffered that college-educated adults might be most effective in this purpose.

Our findings showed that college-educated mentors can help adolescents increase their cultural capital, but only among adolescents whose parents have some experience with the higher 
education system. Why this is true is a bit of a puzzle. Mentors with a college degree may focus more on academic activities and discussions. They may specifically use their time to engage with adolescents in activities that increase cultural capital (e.g., attending museums and visiting cultural locations). Alternatively, they may use their knowledge and clout with parents to convince them to engage in similar activities with their children and provide information on the importance of these activities. It is unclear, however, why mentors with college degrees would not be able to do the same for adolescents whose parents did not attend college. Perhaps these positive effects on cultural capital arise only when parents and mentors share similar beliefs about what adolescents need from the relationship. Moreover, low-SES parents may not be able to commit the time, transportation, and financial resources that cultural capital activities require, even if an outside adult is encouraging them. Scholars should investigate this part of the social capital to cultural capital link in more detail.

Our analysis used experimental data from the BBBSA mentoring program. These data do have some limitations (i.e., moderate sample size, relative disadvantage in the sample, and limited measures of cultural capital), but we believe the experimental nature of the data collection provides a unique opportunity that counterbalances these limitations. Although parents select into the BBBSA program, random assignment to treatment or control conditions and random assignment to specific mentors strengthens our causal claims of the effects of social capital on cultural capital. Unfortunately, the value of this type of social capital in increasing cultural capital is limited to more advantaged families.

A primary limitation of these data is the small sample size. The limited number of adolescents in some categories led to some imprecisely measured coefficients. We report nearly half of our key significant findings with p-values between 0.05 and 0.10 - although most of these 
are between 0.05 and 0.08 . Some may suggest that reporting these coefficients is less than ideal due to standard conventions surrounding p-values in social science. We believe recent debates about strict adherence to statistical significance thresholds versus simply reporting p-values and providing context for the direction of effects supports our decision to report these effects (Amrhein, Greenland, and McShane 2019; Hurlbert, Levine, and Utts 2019; Wasserstein, Schrim, and Lazar 2019). Our figures showing predicted values provide this context and tell a consistent and coherent story, despite some p-values between 0.05 and 0.08 . Moreover, it is important to recall our strong framework for producing causal estimates due to the experimental and longitudinal nature of our data.

We believe that five of our cultural capital measures are well-aligned with prior quantitative work, and our sixth measure (i.e., "get along better with teachers”) is closer to what qualitative work measures. Additionally, the first five measures are activities that mentors can directly participate in with adolescents, but the sixth measure requires passing along knowledge that the adolescent must apply herself. Some researchers have questioned the appropriateness of these traditional quantitative measures (Davies and Rizk 2018). Research, however, finds that these types of measures predict educational achievement and attainment, likely because they help spark intellectual curiosity, knowledge acquisition, and a greater engagement with education.

Our work also suggests that future research should be aware of a slight but essential distinction among three interrelated concepts. Scholars have not clearly defined conceptual boundaries between adolescents' help-seeking behavior, teachers and counselors as sources of social capital, and non-educational actors as sources of social capital. This distinction is crucial because help-seeking behavior can be seen as cultural capital but may also be translated into social capital through interactions with teachers and/or counselors. Moreover, different sources 
of social capital (i.e., teachers and counselors versus other non-school affiliated adults) may

provide different value to adolescents due to the gatekeeper role. Future research should examine this possibility.

Additional broad questions remain that we were unable to address in our research. First, as discussed above, what are the mechanisms that lead adolescents to increase cultural capital in some contexts? Second, are there other ways to attain or increase cultural capital, not just via different kinds of social capital, but more broadly? Third, evidence suggests that race and ethnicity are often paramount in understanding the value of cultural capital, so how do race and ethnicity shape the process of cultural capital acquisition (Richards 2020b)? These questions will provide salient details about cultural capital acquisition that may further clarify the social mobility versus reproduction debate.

Our findings are theoretically interesting but discouraging because they suggest social capital may not be a route for disadvantaged adolescents to acquire or increase cultural capital. These results give credence to the thesis that cultural capital may only work as an engine of social reproduction if disadvantaged students cannot easily or systematically acquire or increase cultural capital. If so, ideas and policies to reduce educational inequality may need to focus more on changing the attitudes and behaviors of institutional gatekeepers rather than disadvantaged families. 
Table 1. Descriptive Statistics

\begin{tabular}{lcccc}
\hline \hline & & Mean / Proportion & \\
& Total & No mentor & $\begin{array}{c}\text { Mentor } \\
\text { w/ col. } \\
\text { deg. }\end{array}$ & $\begin{array}{c}\text { Mentor } \\
\text { w } \geq \text { col. } \\
\text { deg. }\end{array}$ \\
\hline Controls & & & & \\
Age & & & 12.04 & 12.17 \\
Male & 12.25 & 12.33 & 0.534 & 0.617 \\
White & 0.625 & 0.650 & 0.486 & 0.448 \\
Black & 0.423 & 0.398 & 0.370 & 0.409 \\
Hispanic & 0.408 & 0.417 & 0.082 & 0.091 \\
Other Race/Ethnicity & 0.103 & 0.113 & 0.061 & 0.052 \\
Parent $\leq$ high school & 0.066 & 0.072 & 0.589 & 0.565 \\
Parent $\geq$ some college & 0.582 & 0.587 & 0.411 & 0.435 \\
Learning disability & 0.418 & 0.413 & 0.151 & 0.143 \\
GPA (pre-treatment) & 0.155 & 0.161 & 2.67 & 2.83 \\
& 2.77 & 2.77 & & \\
Cultural Capital (pre-treatment) & & & & 2.24 \\
Time spent reading & & & & \\
Museum visits & 2.12 & 2.07 & 2.10 & 1.25 \\
Play attendance & 1.03 & 0.97 & 0.91 & 1.08 \\
Cultural lessons & 0.98 & 0.99 & 0.78 & 0.38 \\
N & 0.37 & 0.35 & 0.42 & 230 \\
\hline
\end{tabular}


Table 2. Social Capital Models Predicting Cultural Capital

(1)

Time Spent
(2)

Museum

Visits
(3)

Play

Attendance
(4)

Cultural

Lessons
(5)

Cultural

Location

Visits

\section{Controls}

Male

Race: Black

Race: Hispanic

Race: Other

Parent $\geq$ some college

GPA (pre-treatment)

Cultural capital (y

variable pre-treatment)

$-0.479^{*}$

$-0.017$

(0.077)

$-0.533^{*}$

$-0.321^{* * *}$

(0.235)

$-0.713^{+}$

(0.081)

(0.379)

$-0.187$

(0.431)

0.155

(0.120)

$-0.080$

(0.141)

$0.501^{*}$

$0.197^{* *}$

(0.214)

(0.072)

0.063

(0.130)

$0.173^{* * *}$

0.093*

(0.046)

$0.139^{* * *}$

(0.033)

$$
-0.183^{*}
$$

$-0.302^{* *}$

$-0.518^{* *}$

(0.113)

(0.177)

$0.440^{*}$

(0.181)

(0.117)

$-0.230$

0.337

(0.318)

(0.126)

0.146

(0.219)

$-0.944^{* *}$

$0.647^{+}$

(0.361)

(0.345)

(0.144)

$0.173^{*}$

(0.075)

$0.104^{*}$

(0.048)

$0.094^{* * *}$

$-0.104$

(0.110)

0.078

(0.174)

$0.198^{* *}$

0.153

(0.102)

(0.073)

$0.217^{* * *}$

(0.021)

(0.031)
(6)

Get Along

Better w/

Teachers

\section{$\underline{\text { Social Capital }}$}

Mentor w/ < col. deg.

-0.014
$(0.296)$
$0.497^{*}$

0.001

0.050

$-0.057$

0.164

$-0.085$

Mentor w/ $\geq$ col. deg.

(0.104)

(0.104)

(0.159)

(0.223)

(0.211)

$0.143^{+}$

$-0.093$

$0.196^{+}$

$0.369^{*}$

0.155

(0.243)

(0.080)

(0.090)

(0.108)

(0.183)

(0.183)

Constant

$\begin{array}{cc}0.765 & 0.757^{+} \\ (1.153) & (0.412)\end{array}$

Observations
$-0.095$
(0.417)

959
$-1.509^{*}$
(0.611)

959
0.508

(0.955)

649
$-0.127$

(0.914)

Note: Each model also controls for age, learning disability, and location (city). The reference category for race is White. Model 1: linear regression. Models 2, 3, \& 4: Poisson regression. Model 5 \& 6: logistic regression. Standard errors in parentheses.

${ }^{+} p<0.10,{ }^{*} p<0.05,{ }^{* *} p<0.01,{ }^{* * *} p<0.001$ 
Table 3. Social Capital Interaction Models Predicting Cultural Capital

\begin{tabular}{|c|c|c|c|c|c|c|}
\hline & $\begin{array}{c}(1) \\
\text { Time } \\
\text { Spent } \\
\text { Reading }\end{array}$ & $\begin{array}{c}(2) \\
\text { Museum } \\
\text { Visits }\end{array}$ & $\begin{array}{c}\text { (3) } \\
\text { Play } \\
\text { Attendance }\end{array}$ & $\begin{array}{c}(4) \\
\text { Cultural } \\
\text { Lessons }\end{array}$ & $\begin{array}{c}\text { (5) } \\
\text { Cultural } \\
\text { Location } \\
\text { Visits }\end{array}$ & $\begin{array}{c}(6) \\
\text { Get Along } \\
\text { Better w/ } \\
\text { Teachers }\end{array}$ \\
\hline \multicolumn{7}{|l|}{ Controls } \\
\hline Male & $\begin{array}{l}-0.468^{*} \\
(0.224)\end{array}$ & $\begin{array}{l}-0.021 \\
(0.077)\end{array}$ & $\begin{array}{l}-0.179^{*} \\
(0.077)\end{array}$ & $\begin{array}{l}-0.301^{* *} \\
(0.113)\end{array}$ & $\begin{array}{l}-0.521^{* *} \\
(0.177)\end{array}$ & $\begin{array}{c}0.077 \\
(0.172)\end{array}$ \\
\hline Race: Black & $\begin{array}{l}-0.521^{*} \\
(0.236)\end{array}$ & $\begin{array}{l}-0.325^{* * *} \\
(0.081)\end{array}$ & $\begin{array}{c}0.069 \\
(0.084)\end{array}$ & $\begin{array}{l}0.263^{*} \\
(0.117)\end{array}$ & $\begin{array}{l}0.439^{*} \\
(0.182)\end{array}$ & $\begin{array}{l}0.371^{*} \\
(0.182)\end{array}$ \\
\hline Race: Hispanic & $\begin{array}{l}-0.725^{+} \\
(0.380)\end{array}$ & $\begin{array}{c}0.171 \\
(0.120)\end{array}$ & $\begin{array}{l}0.399^{* *} \\
(0.126)\end{array}$ & $\begin{array}{l}-0.179 \\
(0.220)\end{array}$ & $\begin{array}{c}0.339 \\
(0.319)\end{array}$ & $\begin{array}{c}0.161 \\
(0.307)\end{array}$ \\
\hline Race: Other & $\begin{array}{l}-0.177 \\
(0.431)\end{array}$ & $\begin{array}{l}-0.085 \\
(0.141)\end{array}$ & $\begin{array}{c}0.155 \\
(0.146)\end{array}$ & $\begin{array}{l}-0.929^{* *} \\
(0.345)\end{array}$ & $\begin{array}{l}0.648^{+} \\
(0.361)\end{array}$ & $\begin{array}{c}0.361 \\
(0.382)\end{array}$ \\
\hline Parent $\geq$ some college & $\begin{array}{l}0.655^{*} \\
(0.272)\end{array}$ & $\begin{array}{c}0.087 \\
(0.094)\end{array}$ & $\begin{array}{l}0.161^{+} \\
(0.095)\end{array}$ & $\begin{array}{l}-0.415^{* *} \\
(0.150)\end{array}$ & $\begin{array}{l}-0.251 \\
(0.270)\end{array}$ & $\begin{array}{l}-0.277 \\
(0.249)\end{array}$ \\
\hline GPA (pre-treatment) & $\begin{array}{c}0.055 \\
(0.130)\end{array}$ & $\begin{array}{l}0.097^{*} \\
(0.046)\end{array}$ & $\begin{array}{l}0.104^{*} \\
(0.048)\end{array}$ & $\begin{array}{l}0.206^{* *} \\
(0.073)\end{array}$ & $\begin{array}{c}0.154 \\
(0.103)\end{array}$ & $\begin{array}{c}0.052 \\
(0.098)\end{array}$ \\
\hline $\begin{array}{l}\text { Cultural capital (y } \\
\text { variable pre-treatment) }\end{array}$ & $\begin{array}{l}0.173^{* * *} \\
(0.033)\end{array}$ & $\begin{array}{l}0.139^{* * *} \\
(0.023)\end{array}$ & $\begin{array}{l}0.092^{* * *} \\
(0.021)\end{array}$ & $\begin{array}{l}0.226^{* * *} \\
(0.032)\end{array}$ & & \\
\hline \multicolumn{7}{|c|}{ Social Capital / Parental Education Interactions } \\
\hline Mentor w/ < col. deg. & $\begin{array}{c}0.242 \\
(0.386)\end{array}$ & $\begin{array}{l}-0.106 \\
(0.143)\end{array}$ & $\begin{array}{c}0.120 \\
(0.133)\end{array}$ & $\begin{array}{l}-0.203 \\
(0.198)\end{array}$ & $\begin{array}{c}0.033 \\
(0.296)\end{array}$ & $\begin{array}{l}-0.376 \\
(0.273)\end{array}$ \\
\hline Mentor w/ $\geq$ col. deg & $\begin{array}{l}0.632^{*} \\
(0.310)\end{array}$ & $\begin{array}{c}0.003 \\
(0.116)\end{array}$ & $\begin{array}{l}-0.175 \\
(0.124)\end{array}$ & $\begin{array}{l}-0.196 \\
(0.171)\end{array}$ & $\begin{array}{c}0.042 \\
(0.256)\end{array}$ & $\begin{array}{l}-0.028 \\
(0.243)\end{array}$ \\
\hline $\begin{array}{l}\text { Mentor } \mathrm{w} /<\text { col. deg. } \\
\text { X Parent } \geq \text { some college }\end{array}$ & $\begin{array}{l}-0.608 \\
(0.602)\end{array}$ & $\begin{array}{c}0.229 \\
(0.207)\end{array}$ & $\begin{array}{l}-0.177 \\
(0.212)\end{array}$ & $\begin{array}{c}0.381 \\
(0.328)\end{array}$ & $\begin{array}{c}0.348 \\
(0.457)\end{array}$ & $\begin{array}{l}0.766^{+} \\
(0.412)\end{array}$ \\
\hline $\begin{aligned} \text { Mentor } \mathrm{w} / & \geq \text { col. deg } \\
\mathrm{X} \text { Parent } & \geq \text { some college }\end{aligned}$ & $\begin{array}{l}-0.256 \\
(0.501)\end{array}$ & $\begin{array}{l}0.281^{+} \\
(0.160)\end{array}$ & $\begin{array}{c}0.173 \\
(0.178)\end{array}$ & $\begin{array}{l}0.873^{* * *} \\
(0.249)\end{array}$ & $\begin{array}{l}0.651^{+} \\
(0.388)\end{array}$ & $\begin{array}{c}0.441 \\
(0.346)\end{array}$ \\
\hline Constant & $\begin{array}{c}0.647 \\
(1.159)\end{array}$ & $\begin{array}{l}0.812^{*} \\
(0.412)\end{array}$ & $\begin{array}{l}-0.117 \\
(0.420)\end{array}$ & $\begin{array}{l}-1.359^{*} \\
(0.614)\end{array}$ & $\begin{array}{c}0.605 \\
(0.965)\end{array}$ & $\begin{array}{c}0.045 \\
(0.918)\end{array}$ \\
\hline Observations & 959 & 959 & 959 & 959 & 649 & 649 \\
\hline
\end{tabular}

Note: Each model also controls for age, learning disability, and location (city). The reference category for race is White and the references category for social capital/parental education interactions is parent with a high school degree or less and no mentor. Model 1: linear regression. Models 2, 3, \& 4: Poisson regression. Model 5: logistic regression. Standard errors in parentheses.

${ }^{+} p<0.10,{ }^{*} p<0.05,{ }^{* *} p<0.01,{ }^{* * *} p<0.001$ 
Figure 1. Predicted Values - Time Spent Reading

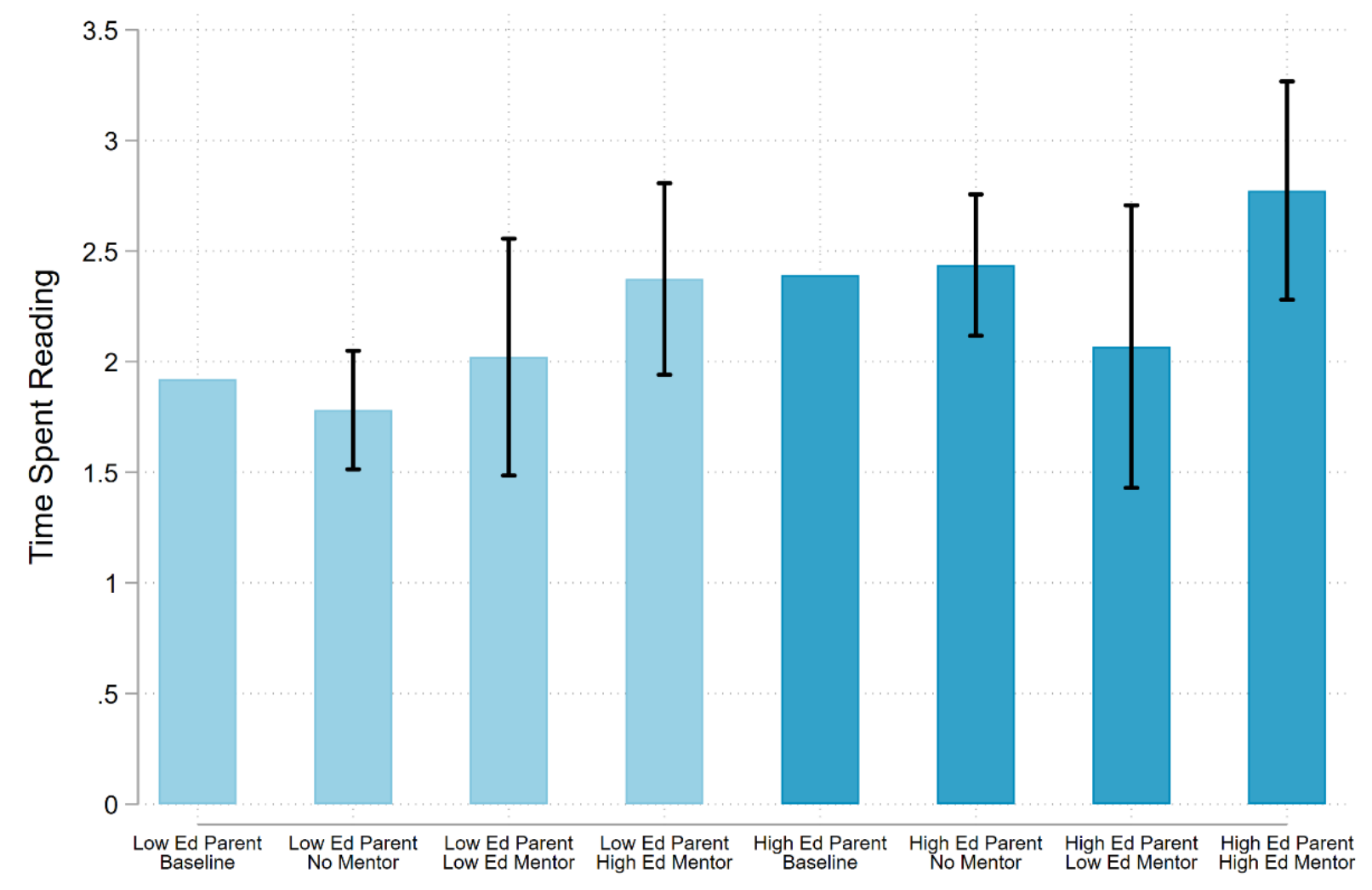

Note: Predicted values based on Model 1 from Table 2. Lines show 95\% confidence interval. 
Figure 2. Predicted Values - Museum Visits

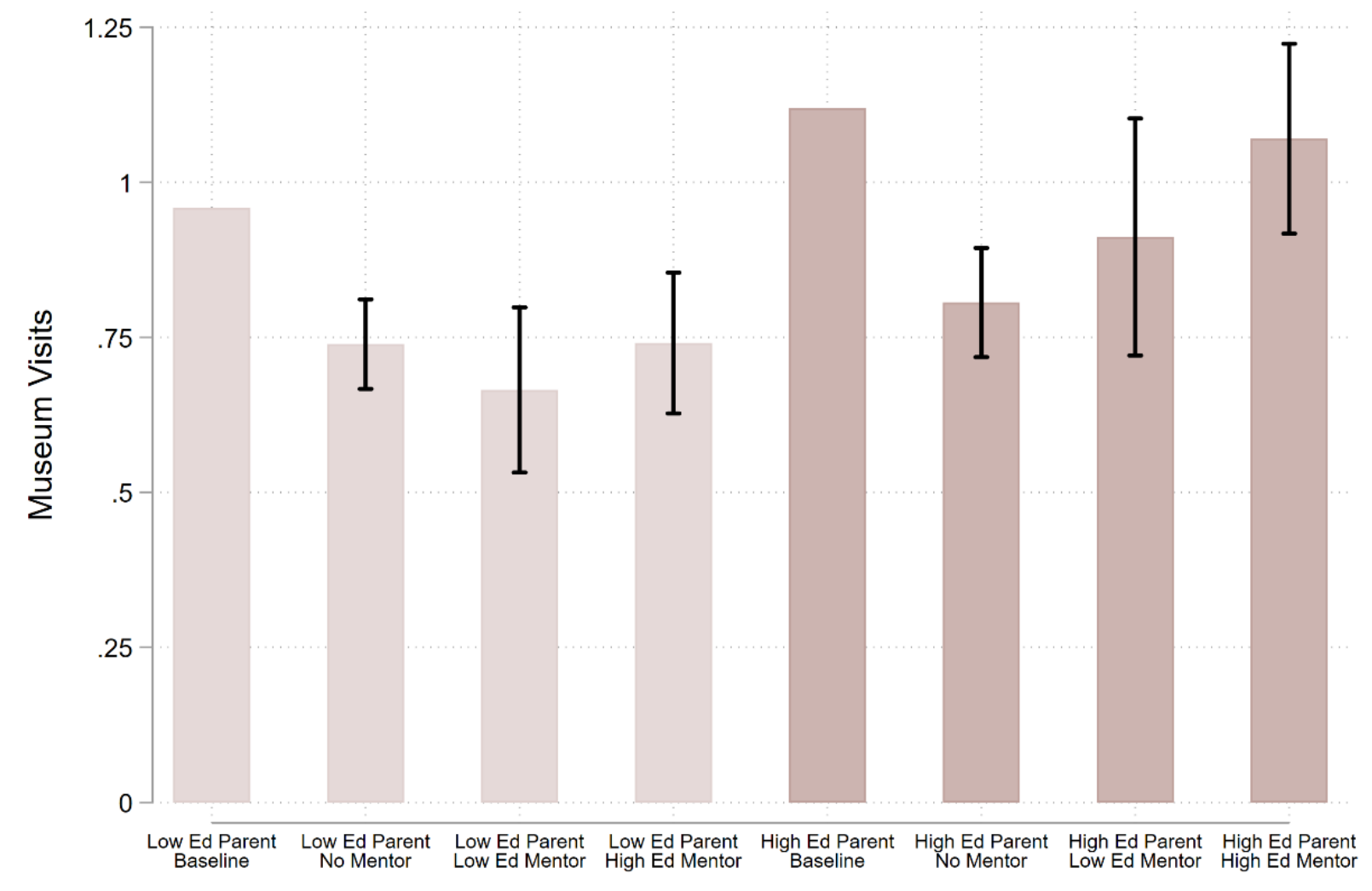

Note: Predicted values based on Model 2 from Table 2. Lines show 95\% confidence interval. 
Figure 3. Predicted Values - Play Attendance

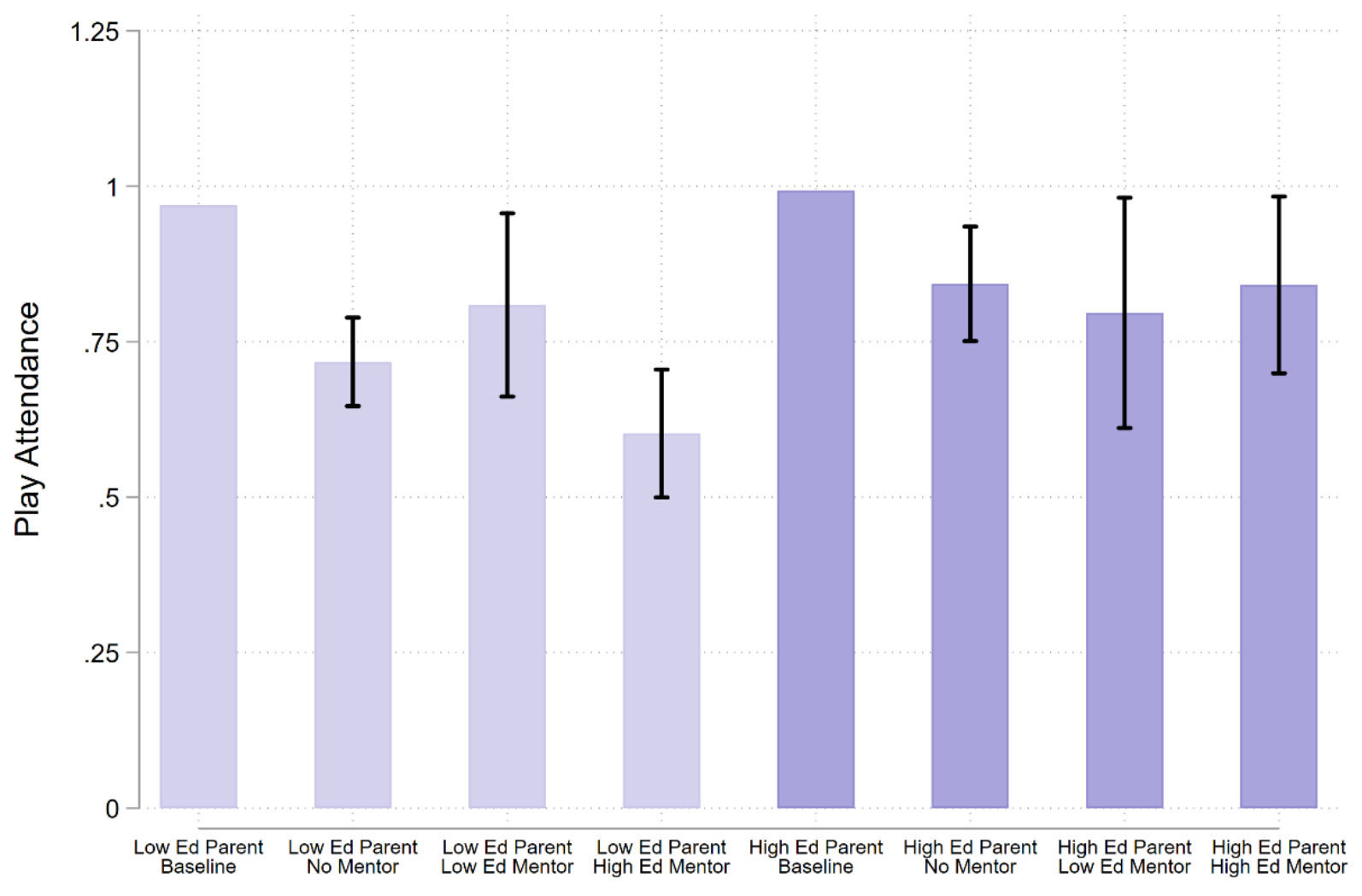

Note: Predicted values based on Model 3 from Table 2. Lines show 95\% confidence interval. 
Figure 4. Predicted Values - Cultural Lessons

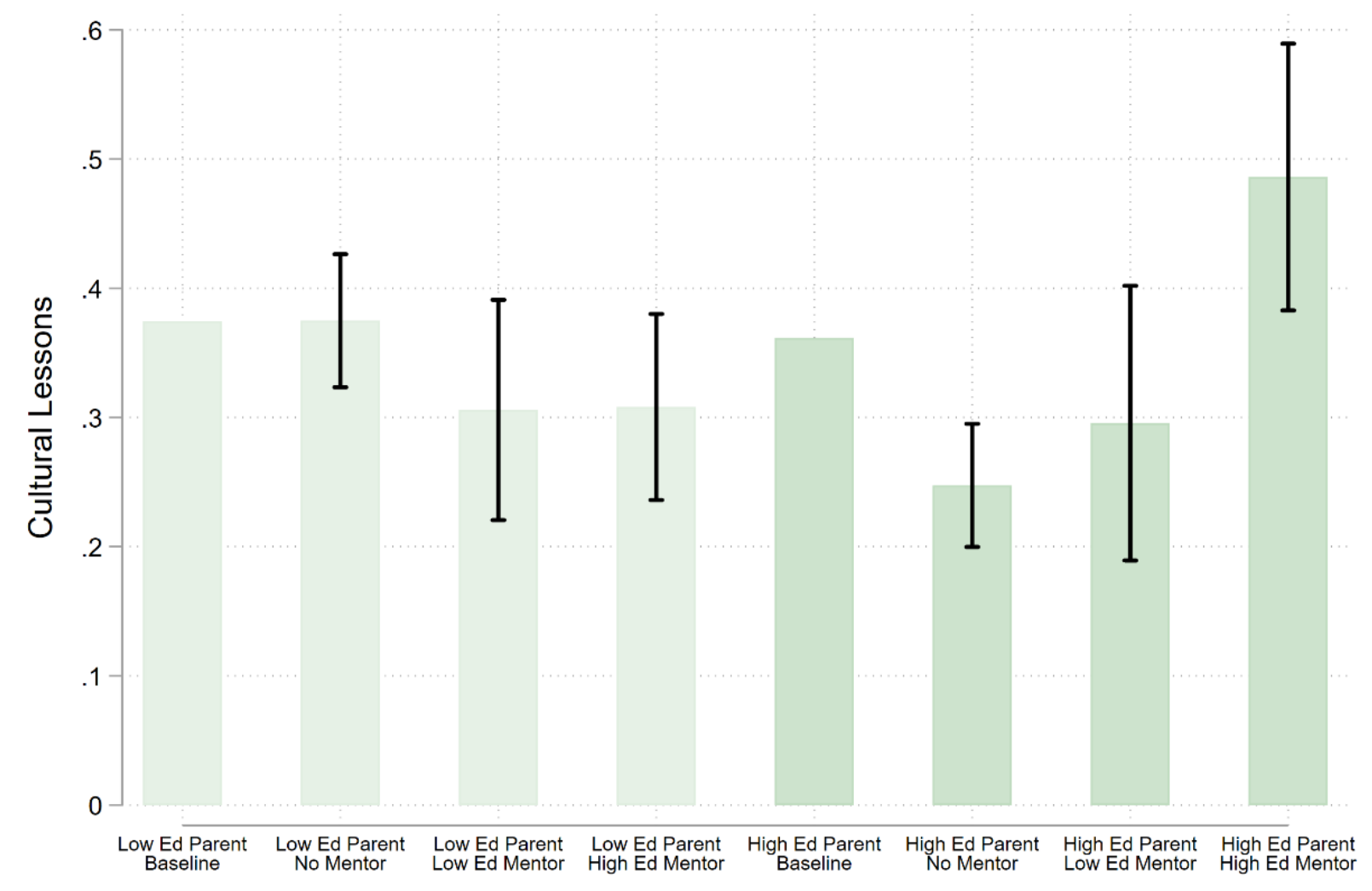

Note: Predicted values based on Model 4 from Table 2. Lines show 95\% confidence interval. 
Figure 5. Predicted Values - Cultural Location Visits

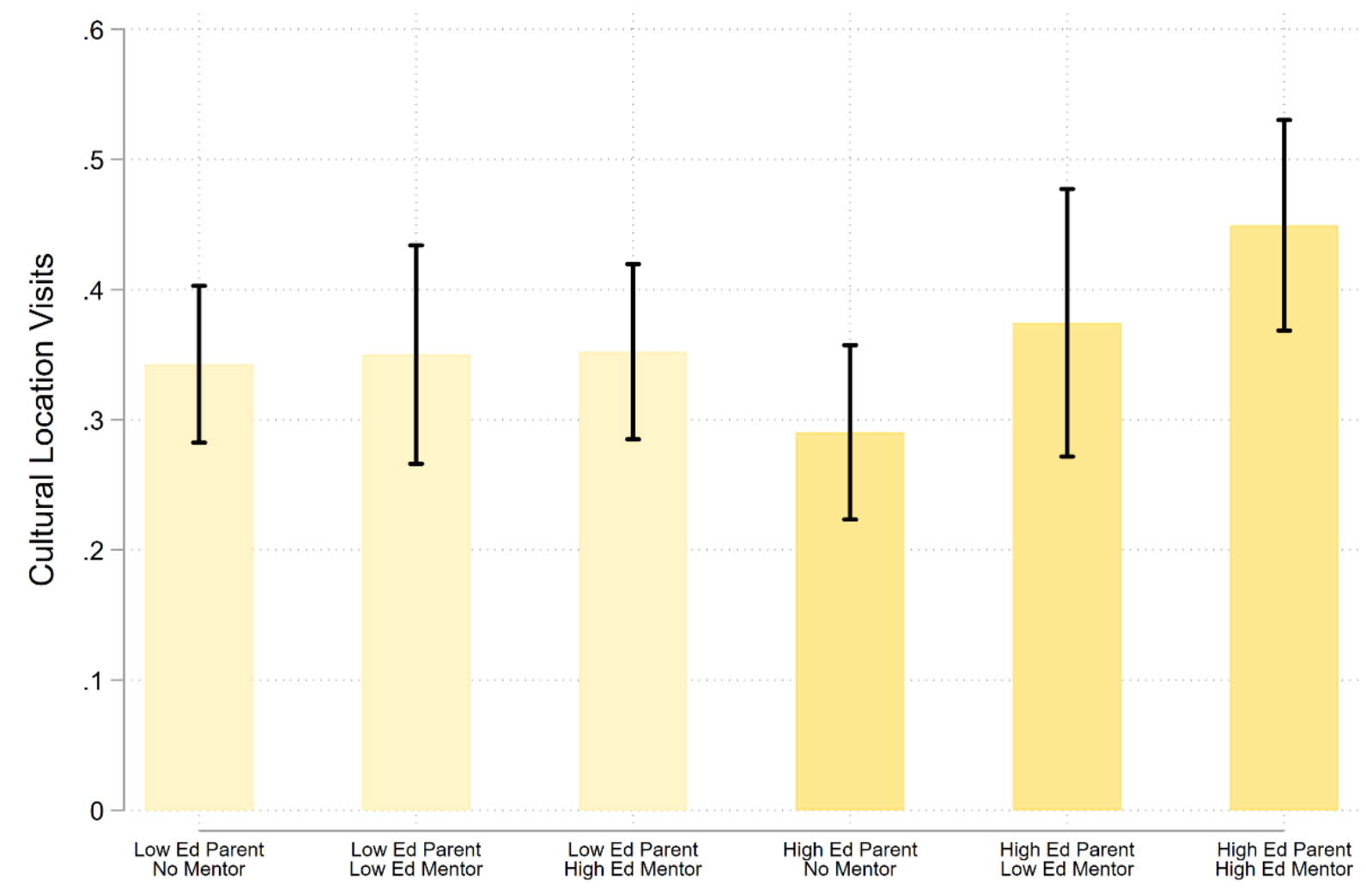

Note: Predicted values based on Model 5 from Table 2. Lines show 95\% confidence interval. 
Figure 6. Predicted Values - Get Along Better with Teachers

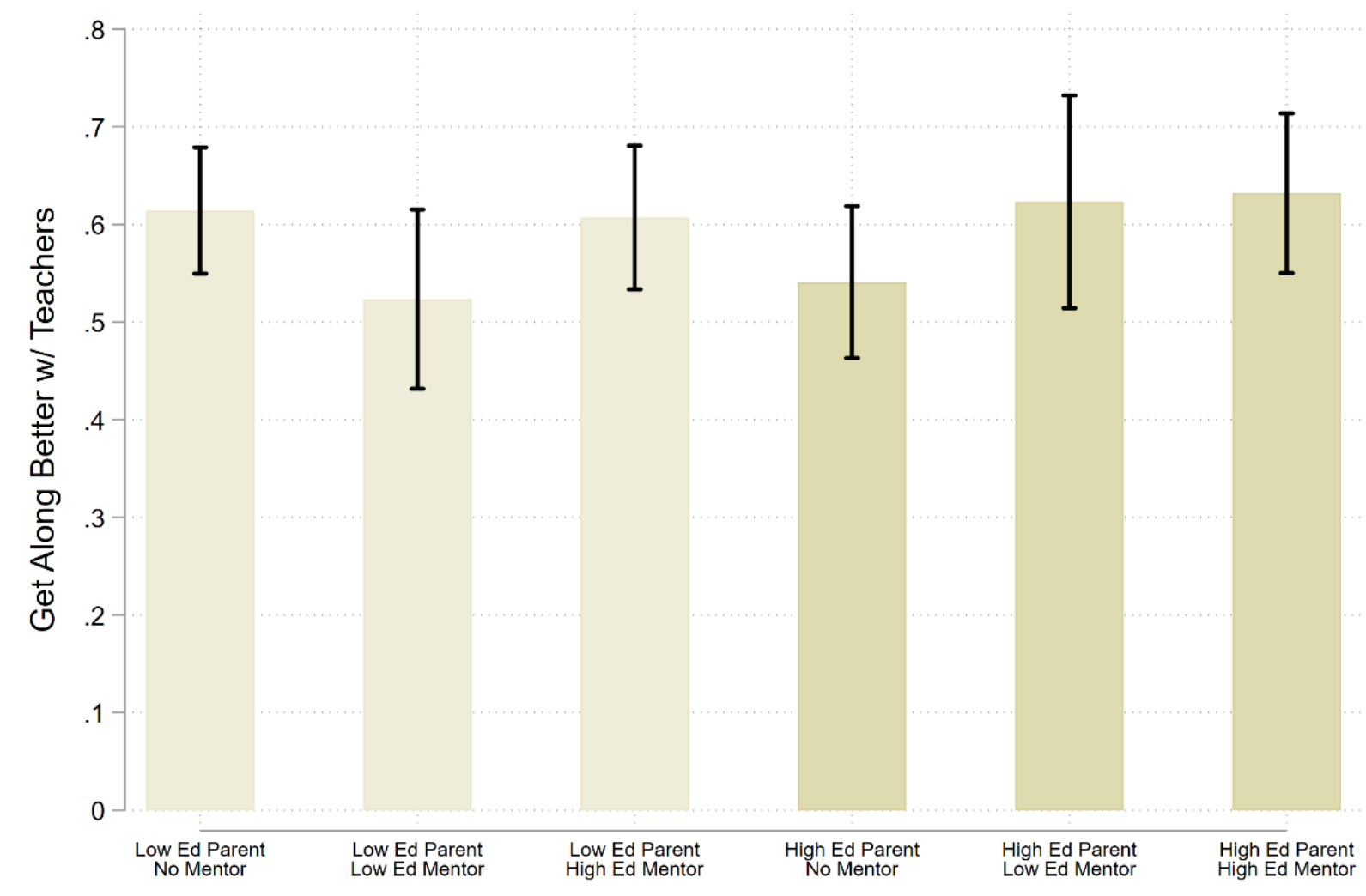

Note: Predicted values based on Model 6 from Table 2. Lines show 95\% confidence interval. 


\section{REFERENCES}

Allison, P. D. (2001). Missing Data. SAGE Publications.

Amrhein, V., Greenland, S., \& McShane, B. (2019). Scientists rise up against statistical significance. Nature, 567(7748), 305-307. https://doi.org/10.1038/d41586-019-00857-9

Andersen, I. G., \& Jæger, M. M. (2015). Cultural capital in context: Heterogeneous returns to cultural capital across schooling environments. Social Science Research, 50, 177-188.

https://doi.org/10.1016/j.ssresearch.2014.11.015

Aries, E. (2008). Race and Class Matters at an Elite College. Temple University Press.

Armstrong, E. A., \& Hamilton, L. T. (2013). Paying for the Party. Harvard University Press.

Aschaffenburg, K., \& Maas, I. (1997). Cultural and Educational Careers: The Dynamics of Social Reproduction. American Sociological Review, 62(4), 573-587. https://doi.org/10.2307/2657427

Berkowitz, R., Moore, H., Astor, R. A., \& Benbenishty, R. (2017). A Research Synthesis of the Associations Between Socioeconomic Background, Inequality, School Climate, and Academic Achievement. Review of Educational Research, 87(2), 425-469. https://doi.org/10.3102/0034654316669821

Bodovski, K., \& Farkas, G. (2008). “Concerted cultivation” and unequal achievement in elementary school. Social Science Research, 37(3), 903-919. https://doi.org/10.1016/j.ssresearch.2008.02.007

Bourdieu, P. (1984). Distinction: A Social Critique of the Judgement of Taste. Harvard University Press.

Bourdieu, P. (1986). The Forms of Capital. In H. Lauder, P. Brown, J.-A. Dillabough, \& A. H. Halsey (Eds.), Education, Globalization, and Social Change (pp. 105-115). Oxford University Press.

Bourdieu, P., \& Passeron, J.-C. (1977). Reproduction in Education, Society, and Culture. SAGE Publications, Inc.

Breinholt, A., \& Jæger, M. M. (2020). How does cultural capital affect educational performance: Signals or skills? The British Journal of Sociology, 71(1), 28-46. https://doi.org/10.1111/1468$\underline{4446.12711}$

Broh, B. A. (2002). Linking Extracurricular Programming to Academic Achievement: Who Benefits and Why? Sociology of Education, 75(1), 69-95. https://doi.org/10.2307/3090254

Calarco, J. M. (2011). “I Need Help!” Social Class and Children’s Help-Seeking in Elementary School. American Sociological Review, 76(6), 862-882. https://doi.org/10.1177/0003122411427177

Calarco, J. M. (2014). Coached for the Classroom: Parents' Cultural Transmission and Children's Reproduction of Educational Inequalities. American Sociological Review, 79(5), 1015-1037. https://doi.org/10.1177/0003122414546931 
Calarco, J. M. (2018). Negotiating Opportunities: How the Middle Class Secures Advantages in School. Oxford University Press.

Carbonaro, W. J. (1998). A Little Help from My Friend's Parents: Intergenerational Closure and Educational Outcomes. Sociology of Education, 71(4), 295-313. https://doi.org/10.2307/2673172

Castilla, E. J., Lan, G. J., \& Rissing, B. A. (2013). Social Networks and Employment: Outcomes (Part 2). Sociology Compass, 7(12), 1013-1026. https://doi.org/10.1111/soc4.12095

Cheadle, J. E. (2008). Educational Investment, Family Context, and Children's Math and Reading Growth from Kindergarten Through the Third Grade. Sociology of Education, 81(1), 1-31. https://doi.org/10.1177/003804070808100101

Cherng, H.-Y. S., Calarco, J. M., \& Kao, G. (2013). Along for the Ride: Best Friends' Resources and Adolescents' College Completion. American Educational Research Journal, 50(1), 76-106. https://doi.org/10.3102/0002831212466689

Coleman, J. S. (1988). Social Capital in the Creation of Human Capital. American Journal of Sociology, 94, S95-S120. https://doi.org/10.1086/228943

Coleman, J. S. (1994). Foundations of Social Theory. Harvard University Press.

Collins, R. (2009a). The Sociology of Philosophies (Vol. 2nd). Harvard University Press.

Collins, R. (2009b). Violence: A Micro-sociological Theory. Princeton University Press.

Collins, R. (2014). Interaction Ritual Chains (Vol. 2nd). Princeton University Press.

Covay, E., \& Carbonaro, W. (2010). After the Bell: Participation in Extracurricular Activities, Classroom Behavior, and Academic Achievement. Sociology of Education, 83(1), 20-45. https://doi.org/10.1177/0038040709356565

Davies, S., \& Rizk, J. (2018). The Three Generations of Cultural Capital Research: A Narrative Review. Review of Educational Research, 88(3), 331-365. https://doi.org/10.3102/0034654317748423

De Graaf, N. D., De Graaf, P. M., \& Kraaykamp, G. (2000). Parental Cultural Capital and Educational Attainment in the Netherlands: A Refinement of the Cultural Capital Perspective. Sociology of Education, 73(2), 92-111. https://doi.org/10.2307/2673239

Dika, S. L., \& Singh, K. (2002). Applications of Social Capital in Educational Literature: A Critical Synthesis. Review of Educational Research, 72(1), 31-60. https://doi.org/10.3102/00346543072001031

DiMaggio, P. (1982). Cultural Capital and School Success: The Impact of Status Culture Participation on the Grades of U.S. High School Students. American Sociological Review, 47(2), 189-201. https://doi.org/10.2307/2094962

DiMaggio, P., \& Mohr, J. (1985). Cultural Capital, Educational Attainment, and Marital Selection. American Journal of Sociology, 90(6), 1231-1261. https://doi.org/10.1086/228209 
Dimaggio, P., \& Mohr, J. (1996). The intergenerational transmission of cultural capital. Research on Social Stratification and Mobility, 167-199.

Domina, T., Penner, A., \& Penner, E. (2017). Categorical Inequality: Schools As Sorting Machines. Annual Review of Sociology, 43(1), 311-330. https://doi.org/10.1146/annurev-soc-060116$\underline{053354}$

DuBois, D. L., \& Silverthorn, N. (2005). Natural Mentoring Relationships and Adolescent Health: Evidence From a National Study. American Journal of Public Health, 95(3), 518-524. https://doi.org/10.2105/AJPH.2003.031476

Dumais, S. A. (2002). Cultural Capital, Gender, and School Success: The Role of Habitus. Sociology of Education, 75(1), 44-68. https://doi.org/10.2307/3090253

Dumais, S. A. (2006). Early childhood cultural capital, parental habitus, and teachers' perceptions. Poetics, 34(2), 83-107. https://doi.org/10.1016/j.poetic.2005.09.003

Dumais, S. A. (2008). Adolescents’ Time Use and Academic Achievement: A Test of the Reproduction and Mobility Models*. Social Science Quarterly, 89(4), 867-886. https://doi.org/10.1111/j.1540-6237.2008.00588.x

Dumais, S. A., Kessinger, R. J., \& Ghosh, B. (2012). Concerted Cultivation and Teachers' Evaluations of Students: Exploring the Intersection of Race and Parents' Educational Attainment. Sociological Perspectives, 55(1), 17-42. https://doi.org/10.1525/sop.2012.55.1.17

Dumais, S. A., \& Ward, A. (2010). Cultural capital and first-generation college success. Poetics, 38(3), 245-265. https://doi.org/10.1016/j.poetic.2009.11.011

Eby, L. T., Allen, T. D., Evans, S. C., Ng, T., \& DuBois, D. L. (2008). Does mentoring matter? A multidisciplinary meta-analysis comparing mentored and non-mentored individuals. Journal of Vocational Behavior, 72(2), 254-267. https://doi.org/10.1016/j.jvb.2007.04.005

Entwisle, D. R., \& Alexander, K. L. (1993). Entry Into School: The Beginning School Transition and Educational Stratification in the United States. Annual Review of Sociology, 19(1), 401-423. https://doi.org/10.1146/annurev.so.19.080193.002153

Erickson, L. D., McDonald, S., \& Elder, G. H. (2009). Informal Mentors and Education: Complementary or Compensatory Resources? Sociology of Education, 82(4), 344-367. https://doi.org/10.1177/003804070908200403

Farkas, G. (2017). Human Capital or Cultural Capital?: Ethnicity and Poverty Groups in an Urban School District (2nd ed.). Routledge.

Farkas, G., Grobe, R. P., Sheehan, D., \& Shuan, Y. (1990). Cultural Resources and School Success: Gender, Ethnicity, and Poverty Groups within an Urban School District. American Sociological Review, 55(1), 127-142. https://doi.org/10.2307/2095708

Farmer-Hinton, R. L. (2008). Social Capital and College Planning: Students of Color Using School Networks for Support and Guidance. Education and Urban Society, 41(1), 127-157. https://doi.org/10.1177/0013124508321373 
Gaddis, S. M. (2012). What's in a Relationship? An Examination of Social Capital, Race and Class in Mentoring Relationships. Social Forces, 90(4), 1237-1269. https://doi.org/10.1093/sf/sos003

Gaddis, S. M. (2013). The influence of habitus in the relationship between cultural capital and academic achievement. Social Science Research, 42(1), 1-13. https://doi.org/10.1016/j.ssresearch.2012.08.002

Gaddis, S. M. (2015). Discrimination in the Credential Society: An Audit Study of Race and College Selectivity in the Labor Market. Social Forces, 93(4), 1451-1479. https://doi.org/10.1093/sf/sou111

Gonzales, R. G. (2011). Learning to Be Illegal: Undocumented Youth and Shifting Legal Contexts in the Transition to Adulthood. American Sociological Review, 76(4), 602-619. https://doi.org/10.1177/0003122411411901

Gonzales, R. G. (2016). Lives in Limbo: Undocumented and Coming of Age in America. Univ of California Press.

Granovetter, M. S. (1973). The Strength of Weak Ties. American Journal of Sociology, 78(6), 13601380. https://doi.org/10.1086/225469

Greene, J. P., Erickson, H. H., Watson, A. R., \& Beck, M. I. (2018). The Play’s the Thing: Experimentally Examining the Social and Cognitive Effects of School Field Trips to Live Theater Performances. Educational Researcher, 47(4), 246-254. https://doi.org/10.3102/0013189X18761034

Hardie, J. H. (2015). The Best Laid Plans: Social Capital in the Development of Girls’ Educational and Occupational Plans. Social Problems, 62(2), 241-265. https://doi.org/10.1093/socpro/spv003

Hardie, J. H. (2018). Rethinking School-Based Ties: Social Class and the Role of Institutional Agents in Adolescents’ College Plans. Teachers College Record, 120, 1-49.

Hofferth, S. L., Boisjoly, J., \& Duncan, G. J. (1998). Parents’ Extrafamilial Resources and Children’s School Attainment. Sociology of Education, 71(3), 246-268. https://doi.org/10.2307/2673204

Holland, M. M. (2015). Trusting Each Other: Student-Counselor Relationships in Diverse High Schools. Sociology of Education, 88(3), 244-262. https://doi.org/10.1177/0038040715591347

Holland, M. M. (2019). Divergent Paths to College: Race, Class, and Inequality in High Schools. Rutgers University Press.

Horvat, E. M., Weininger, E. B., \& Lareau, A. (2003). From Social Ties to Social Capital: Class Differences in the Relations Between Schools and Parent Networks. American Educational Research Journal, 40(2), 319-351. https://doi.org/10.3102/00028312040002319

Hu, A., \& Yin, C. (2020). The Distinction between the Absolute and Relative Advantages of Cultural Capital: Different Conceptualizations, Different Consequences. Sociology, 0038038520973588. https://doi.org/10.1177/0038038520973588 
Hurlbert, S. H., Levine, R. A., \& Utts, J. (2019). Coup de Grâce for a Tough Old Bull: “Statistically Significant” Expires. The American Statistician, 73(sup1), 352-357. https://doi.org/10.1080/00031305.2018.1543616

Jack, A. A. (2014). Culture Shock Revisited: The Social and Cultural Contingencies to Class Marginality. Sociological Forum, 29(2), 453-475. https://doi.org/10.1111/socf.12092

Jack, A. A. (2016). (No) Harm in Asking: Class, Acquired Cultural Capital, and Academic Engagement at an Elite University. Sociology of Education, 89(1), 1-19. https://doi.org/10.1177/0038040715614913

Jack, A. A. (2019). The Privileged Poor: How Elite Colleges Are Failing Disadvantaged Students. Harvard University Press.

Jæger, M. M. (2009). Equal Access but Unequal Outcomes: Cultural Capital and Educational Choice in a Meritocratic Society. Social Forces, 87(4), 1943-1971. https://doi.org/10.1353/sof.0.0192

Jæger, M. M. (2011). Does Cultural Capital Really Affect Academic Achievement? New Evidence from Combined Sibling and Panel Data. Sociology of Education, 84(4), 281-298. https://doi.org/10.1177/0038040711417010

Jæger, M. M., \& Breen, R. (2016). A Dynamic Model of Cultural Reproduction. American Journal of Sociology, 121(4), 1079-1115. https://doi.org/10.1086/684012

Jæger, M. M., \& Møllegaard, S. (2017). Cultural capital, teacher bias, and educational success: New evidence from monozygotic twins. Social Science Research, 65, 130-144. https://doi.org/10.1016/j.ssresearch.2017.04.003

Kalmijn, M., \& Kraaykamp, G. (1996). Race, Cultural Capital, and Schooling: An Analysis of Trends in the United States. Sociology of Education, 69(1), 22-34. https://doi.org/10.2307/2112721

Kisida, B., Greene, J. P., \& Bowen, D. H. (2014). Creating Cultural Consumers: The Dynamics of Cultural Capital Acquisition. Sociology of Education, 87(4), 281-295. https://doi.org/10.1177/0038040714549076

Kozlowski, K. P. (2015). Culture or Teacher Bias? Racial and Ethnic Variation in Student-Teacher Effort Assessment Match/Mismatch. Race and Social Problems, 7(1), 43-59. https://doi.org/10.1007/s12552-014-9138-X

Lacoe, J., Painter, G. D., \& Williams, D. (2020). Museums as Classrooms: The Academic and Behavioral Impacts of "School in the Park.” AERA Open, 6(3), 2332858420940309. https://doi.org/10.1177/2332858420940309

Lamont, M., \& Lareau, A. (1988). Cultural Capital: Allusions, Gaps and Glissandos in Recent Theoretical Developments. Sociological Theory, 6(2), 153-168. https://doi.org/10.2307/202113

Lareau, A. (1987). Social Class Differences in Family-School Relationships: The Importance of Cultural Capital. Sociology of Education, 60(2), 73-85. https://doi.org/10.2307/2112583 
Lareau, A. (2000). Home Advantage: Social Class and Parental Intervention in Elementary Education (2nd ed.). Rowman \& Littlefield Publishers.

Lareau, A. (2002). Invisible Inequality: Social Class and Childrearing in Black Families and White Families. American Sociological Review, 67(5), 747-776. https://doi.org/10.2307/3088916

Lareau, A. (2011). Unequal Childhoods: Class, Race, and Family Life (2nd ed.). University of California Press.

Lareau, A. (2015). Cultural Knowledge and Social Inequality. American Sociological Review, 80(1), 1-27. https://doi.org/10.1177/0003122414565814

Lareau, A., \& Calarco, J. M. (2012). Class, Cultural Capital, and Institutions: The Case of Families and Schools. In S. T. Fiske \& H. R. Markus (Eds.), Facing Social Class: How Societal Rank Influences Interaction (pp. 61-86). Russell Sage Foundation.

Lareau, A., \& Horvat, E. M. (1999). Moments of Social Inclusion and Exclusion Race, Class, and Cultural Capital in Family-School Relationships. Sociology of Education, 72(1), 37-53. https://doi.org/10.2307/2673185

Lareau, A., \& Weininger, E. B. (2003). Cultural capital in educational research: A critical assessment. Theory and Society, 32(5), 567-606. https://doi.org/10.1023/B:RYSO.0000004951.04408.b0

Lauen, D. L., \& Gaddis, S. M. (2013). Exposure to Classroom Poverty and Test Score Achievement: Contextual Effects or Selection? American Journal of Sociology, 118(4), 943-979. https://doi.org/10.1086/668408

Lee, E. M., \& Kramer, R. (2013). Out with the Old, In with the New? Habitus and Social Mobility at Selective Colleges. Sociology of Education, 86(1), 18-35. https://doi.org/10.1177/0038040712445519

Lehmann, W. (2007). “I just didn’t feel like I fit in”: The role of habitus in university dropout decisions. Canadian Journal of Higher Education, 37(2), 89-110. https://doi.org/10.47678/cjhe.v37i2.542

Lin, N. (2002). Social Capital: A Theory of Social Structure and Action. Cambridge University Press.

Lin, N. (2008). A Network Theory of Social Capital. In D. Castiglione, J. W. Van Deth, \& G. Wolleb (Eds.), The Handbook of Social Capital (pp. 50-69). Oxford University Press.

Lin, N., Ensel, W. M., \& Vaughn, J. C. (1981). Social Resources and Strength of Ties: Structural Factors in Occupational Status Attainment. American Sociological Review, 46(4), 393-405. https://doi.org/10.2307/2095260

Lin, N., Vaughn, J. C., \& Ensel, W. M. (1981). Social Resources and Occupational Status Attainment. Social Forces, 59(4), 1163-1181. https://doi.org/10.1093/sf/59.4.1163

Matsuoka, R. (2019). Concerted cultivation developed in a standardized education system. Social Science Research, 77, 161-178. https://doi.org/10.1016/j.ssresearch.2018.08.011 
McDonald, S., Gaddis, S. M., Trimble, L. B., \& Hamm, L. (2013). Frontiers of Sociological Research on Networks, Work, and Inequality. In S. Mcdonald (Ed.), Networks, Work and Inequality (Vol. 24, pp. 1-41). Emerald Group Publishing Limited. https://doi.org/10.1108/S02772833(2013)0000024005

McDonald, S., \& Lambert, J. (2014). The Long Arm of Mentoring: A Counterfactual Analysis of Natural Youth Mentoring and Employment Outcomes in Early Careers. American Journal of Community Psychology, 54(3-4), 262-273. https://doi.org/10.1007/s10464-014-9670-2

McKillip, M. E. M., Rawls, A., \& Barry, C. (2012). Improving College Access: A Review of Research on the Role of High School Counselors. Professional School Counseling, 16(1), 2156759X1201600106. https://doi.org/10.1177/2156759X1201600106

McNeal, R. B., Jr. (1999). Parental Involvement as Social Capital: Differential Effectiveness on Science Achievement, Truancy, and Dropping Out*. Social Forces, 78(1), 117-144. https://doi.org/10.1093/sf/78.1.117

Miranda-Chan, T., Fruiht, V., Dubon, V., \& Wray-Lake, L. (2016). The Functions and Longitudinal Outcomes of Adolescents’ Naturally Occurring Mentorships. American Journal of Community Psychology, 57(1-2), 47-59. https://doi.org/10.1002/ajcp.12031

Morgan, S. L., \& Sørensen, A. B. (1999). Parental Networks, Social Closure, and Mathematics Learning: A Test of Coleman's Social Capital Explanation of School Effects. American Sociological Review, 64(5), 661-681. https://doi.org/10.2307/2657368

Mouw, T. (2003). Social Capital and Finding a Job: Do Contacts Matter? American Sociological Review, 68(6), 868-898. https://doi.org/10.2307/1519749

Mouw, T. (2006). Estimating the Causal Effect of Social Capital: A Review of Recent Research. Annual Review of Sociology, 32(1), 79-102. https://doi.org/10.1146/annurev.soc.32.061604.123150

Noble, J., \& Davies, P. (2009). Cultural capital as an explanation of variation in participation in higher education. British Journal of Sociology of Education, 30(5), 591-605.

https://doi.org/10.1080/01425690903101098

Nora, A. (2004). The Role of Habitus and Cultural Capital in Choosing a College, Transitioning From High School to Higher Education, and Persisting in College Among Minority and Nonminority Students. Journal of Hispanic Higher Education, 3(2), 180-208. https://doi.org/10.1177/1538192704263189

O’Connor, C. (2000). Dreamkeeping in the Inner City: Diminishing the Divide Between Aspirations and Expectations. In S. Danziger \& A. C. Lin (Eds.), Coping With Poverty: The Social Contexts of Neighborhood, Work, and Family in the African-American Community. University of Michigan Press.

Ostrove, J. M., \& Long, S. M. (2007). Social Class and Belonging: Implications for College Adjustment. The Review of Higher Education, 30(4), 363-389.

https://doi.org/10.1353/rhe.2007.0028 
Pedulla, D. S., \& Pager, D. (2019). Race and Networks in the Job Search Process. American Sociological Review, 84(6), 983-1012. https://doi.org/10.1177/0003122419883255

Pike, G. R., \& Kuh, G. D. (2005). First- and Second-Generation College Students: A Comparison of Their Engagement and Intellectual Development. The Journal of Higher Education, 76(3), 276300. https://doi.org/10.1353/jhe.2005.0021

Portes, A. (1998). Social Capital: Its Origins and Applications in Modern Sociology. Annual Review of Sociology, 24(1), 1-24. https://doi.org/10.1146/annurev.soc.24.1.1

Ream, R. K., \& Palardy, G. J. (2008). Reexamining Social Class Differences in the Availability and the Educational Utility of Parental Social Capital. American Educational Research Journal, 45(2), 238-273. https://doi.org/10.3102/0002831207308643

Richards, B. N. (2020a). Help-Seeking Behaviors as Cultural Capital: Cultural Guides and the Transition from High School to College among Low-Income First Generation Students. Social Problems, spaa023. https://doi.org/10.1093/socpro/spaa023

Richards, B. N. (2020b). When class is colorblind: A race-conscious model for cultural capital research in education. Sociology Compass, 14(7), e12789. https://doi.org/10.1111/soc4.12786

Rivera, L. A. (2011). Ivies, extracurriculars, and exclusion: Elite employers' use of educational credentials. Research in Social Stratification and Mobility, 29(1), 71-90. https://doi.org/10.1016/j.rssm.2010.12.001

Rivera, L. A. (2012). Hiring as Cultural Matching: The Case of Elite Professional Service Firms. American Sociological Review, 77(6), 999-1022. https://doi.org/10.1177/0003122412463213

Roksa, J., \& Potter, D. (2011a). Parenting and Academic Achievement: Intergenerational Transmission of Educational Advantage. Sociology of Education, 84(4), 299-321. https://doi.org/10.1177/0038040711417013

Roksa, J., \& Potter, D. (2011b). Parenting and Academic Achievement: Intergenerational Transmission of Educational Advantage. Sociology of Education, 84(4), 299-321. https://doi.org/10.1177/0038040711417013

Roksa, J., \& Robinson, K. J. (2017). Cultural capital and habitus in context: The importance of high school college-going culture. British Journal of Sociology of Education, 38(8), 1230-1244. https://doi.org/10.1080/01425692.2016.1251301

Roscigno, V. J., \& Ainsworth-Darnell, J. W. (1999). Race, Cultural Capital, and Educational Resources: Persistent Inequalities and Achievement Returns. Sociology of Education, 72(3), 158-178. https://doi.org/10.2307/2673227

Sablan, J. R., \& Tierney, W. G. (2014). The Changing Nature of Cultural Capital. In M. B. Paulsen (Ed.), Higher Education: Handbook of Theory and Research: Volume 29 (pp. 153-188). Springer Netherlands. https://doi.org/10.1007/978-94-017-8005-6_4 
Sirin, S. R. (2005). Socioeconomic Status and Academic Achievement: A Meta-Analytic Review of Research. Review of Educational Research, 75(3), 417-453.

https://doi.org/10.3102/00346543075003417

Stanton-Salazar, R. (1997). A Social Capital Framework for Understanding the Socialization of Racial Minority Children and Youths. Harvard Educational Review, 67(1), 1-41. https://doi.org/10.17763/haer.67.1.140676g74018u73k

Stanton-Salazar, R. D. (2001). Manufacturing Hope and Despair: The School and Kin Support Networks of U.S.-Mexican Youth. Teachers College Press.

Stanton-Salazar, R. D. (2011). A Social Capital Framework for the Study of Institutional Agents and Their Role in the Empowerment of Low-Status Students and Youth. Youth \& Society, 43(3), 1066-1109. https://doi.org/10.1177/0044118X10382877

Stanton-Salazar, R. D., \& Dornbusch, S. M. (1995). Social Capital and the Reproduction of Inequality: Information Networks among Mexican-Origin High School Students. Sociology of Education, 68(2), 116-135. https://doi.org/10.2307/2112778

Stanton-Salazar, R. D., \& Spina, S. U. (2003). Informal Mentors and Role Models in the Lives of Urban Mexican-Origin Adolescents. Anthropology \& Education Quarterly, 34(3), 231-254. https://doi.org/10.1525/aeq.2003.34.3.231

Stephens, N. M., Townsend, S. S. M., Markus, H. R., \& Phillips, L. T. (2012). A cultural mismatch: Independent cultural norms produce greater increases in cortisol and more negative emotions among first-generation college students. Journal of Experimental Social Psychology, 48(6), 1389-1393. https://doi.org/10.1016/j.jesp.2012.07.008

Stevens, M. L. (2007). Creating a Class: College Admissions and the Education of Elites. Harvard University Press.

Streib, J. (2011). Class Reproduction by Four Year Olds. Qualitative Sociology, 34(2), 337-352. https://doi.org/10.1007/s11133-011-9193-1

Stuber, J. M. (2011). Inside the College Gates: How Class and Culture Matter in Higher Education. Lexington Books.

Tierney, J. P., Grossman, J. B., \& Resch, N. L. (1995). Making a Difference: An Impact Study of Big Brothers Big Sisters. Public/Private Ventures.

Tramonte, L., \& Willms, J. D. (2010). Cultural capital and its effects on education outcomes. Economics of Education Review, 29(2), 200-213. https://doi.org/10.1016/j.econedurev.2009.06.003

Trimble, L. B., \& Kmec, J. A. (2011). The Role of Social Networks in Getting a Job. Sociology Compass, 5(2), 165-178. https://doi.org/10.1111/j.1751-9020.2010.00353.x

Vallejo, J. (2012). Barrios to Burbs: The Making of the Mexican American Middle Class. Stanford University Press. 
Wasserstein, R. L., Schirm, A. L., \& Lazar, N. A. (2019). Moving to a World Beyond "p < 0.05.” The American Statistician, 73(sup1), 1-19. https://doi.org/10.1080/00031305.2019.1583913

Wildhagen, T. (2009). Why Does Cultural Capital Matter for High School Academic Performance? An Empirical Assessment of Teacher-Selection and Self-Selection Mechanisms as Explanations of the Cultural Capital Effect. The Sociological Quarterly, 50(1), 173-200. https://doi.org/10.1111/j.1533-8525.2008.01137.x

Wildhagen, T. (2010). Capitalizing on Culture: How Cultural Capital Shapes Educational Experiences and Outcomes. Sociology Compass, 4(7), 519-531. https://doi.org/10.1111/j.17519020.2010.00296.X

Yee, A. (2016). The Unwritten Rules of Engagement: Social Class Differences in Undergraduates' Academic Strategies. The Journal of Higher Education, 87(6), 831-858. https://doi.org/10.1080/00221546.2016.11780889

Zarifa, D., Kim, J., Seward, B., \& Walters, D. (2018). What's Taking You So Long? Examining the Effects of Social Class on Completing a Bachelor's Degree in Four Years. Sociology of Education, 91(4), 290-322. https://doi.org/10.1177/0038040718802258 